\title{
Genome-Wide Mapping of Loci for Adult-Plant Resistance to Stripe Rust in Durum Wheat Svevo Using the 90K SNP Array
}

\author{
Xinli Zhou, ${ }^{1}$ Xiao Zhong, ${ }^{1}$ Jonatan Roter, ${ }^{2}$ Xin Li, ${ }^{1}$ Qiang Yao, ${ }^{3}$ Jiahui Yan, ${ }^{3}$ Suizhuang Yang, ${ }^{1}$ Qingyun Guo, ${ }^{3}$ Assaf Distelfeld, ${ }^{2}$ \\ Hanan Sela, ${ }^{2, \dagger}$ and Zhensheng Kang ${ }^{4}$, \\ ${ }^{1}$ Wheat Research Institute, School of Life Sciences and Engineering, Southwest University of Science and Technology, Mia- \\ nyang, Sichuan 621010, People's Republic of China \\ 2 The Institute for Cereal Crops Improvement Tel-Aviv University; Institute of Evolution, Department of Evolutionary and En- \\ vironmental Biology, University of Haifa; Tel Aviv 6139001, Israel \\ ${ }^{3}$ Key Laboratory of Agricultural Integrated Pest Management, Qinghai Province, Scientific Observing and Experimental Station \\ of Crop Pest in Xining, Ministry of Agriculture, Academy of Agriculture and Forestry Science, Qinghai University, Xining, \\ Qinghai 810016, People's Republic of China \\ ${ }^{4}$ State Key Laboratory of Crop Stress Biology in Arid Areas and College of Plant Protection, Northwest A\&F University, Yan- \\ gling, Shaanxi 712100, People's Republic of China
}

\begin{abstract}
Stripe rust is a foliar disease in wheat caused by Puccinia striiformis $\mathrm{f}$. tritici. The best way to protect wheat from this disease is by growing resistant cultivars. Tetraploid wheat can serve as a good source of valuable genetic diversity for various traits. Here, we report the mapping of nine stripe rust resistance quantitative trait loci (QTL) effective against $P$. striiformis $\mathrm{f}$. tritici in China and Israel. We used recombinant inbred lines (RILs) developed from a cross between the durum wheat cultivar Svevo and Triticum dicoccoides accession Zavitan. By genotyping

corresponding to the region of 670.7 to $671.5 \mathrm{Mb}$ on the Chinese Spring chromosome arm 1BL. Of the other eight minor-effect stripe rust QTL, seven were from Svevo and mapped on chromosomes 1A, 1B, 2B, 3A, $4 \mathrm{~A}$, and $5 \mathrm{~A}$, and one was from Zavitan and mapped on chromosome 2A. Several QTL with epistatic effects were identified as well. The markers linked to the resistance QTL can be useful in marker-assisted selection for incorporation of these resistance QTL into both durum and common wheat cultivars.
\end{abstract} the RIL population of 137 lines using the wheat $90 \mathrm{~K}$ single-nucleotide polymorphism array, we mapped an adult-plant resistance locus QYrsv. swust-1BL.1, the most effective QTL, within a 0.75 -centimorgan region in T. turgidum subsp. durum 'Svevo' on chromosome arm 1BL,
Keywords: cereals and grains, cultivar/resistance, disease management, field crops, fungi, QTL mapping, stripe rust, wild emmer wheat, yellow rust
Wheat is a widely used cereal for human consumption. The two most important cultivated wheat species are Triticum aestivum L. (common wheat) and T. turgidum L. subsp. durum (durum wheat). T. aestivum is a hexaploid species possessing the genome AABBDD, whereas T. durum and T. dicoccoides (Körn. ex Asch. \& Graebn.) Schweinf. (wild emmer), the progenitor of durum, are tetraploid, with genome composition AABB.

In recent years, wheat genomics has developed rapidly, and the completion of wheat genome sequencing and gene annotation facilitates the breeding of wheat cultivars for high yield and resistance to

${ }^{\dagger}$ Corresponding authors: Z. Kang; kangzs@nwsuaf.edu.cn; and H. Sela; hans@013.net

Funding: This study was financially supported by the International S\&T Cooperation Program of China (2015DFG32340) and Israel Ministry of Agriculture (number 13-01-0006), and was partially funded by the Longshan Academic Talent Research Support Program of SWUST (number 17LZX5), Open Project of the Key Laboratory of Agricultural Integrated Pest Management, Academy of Agriculture and Forestry Sciences, Qinghai University, China (QHIIP-20017-02), and the National Key Research and Development Program of China (2017YFD0100905).

Xinli Zhou and Xiao Zhong have contributed equally to this study.

*The $\boldsymbol{e}$-Xtra logo stands for "electronic extra" and indicates that supplementary tables are published online.

The author(s) declare no conflict of interest.

Accepted for publication 28 October 2020.

C 2021 The American Phytopathological Society abiotic and biotic stresses. Three wheat genome assemblies were published recently: wild emmer, bread wheat, and durum wheat (Avni et al. 2017; Maccaferri et al. 2019; The International Wheat Genome Sequencing Consortium (IWGSC) 2018). These genome assemblies have enabled fine mapping, cloning, and functional analysis of genes for agronomic traits, and accelerated the genetic improvement and the molecular-assisted breeding of cultivated wheat.

Stripe rust (yellow rust $[\mathrm{Yr}]$ ), caused by Puccinia striiformis $\mathrm{f}$. tritici Erikss., is one of the most damaging diseases of common wheat and durum wheat worldwide (Chen 2005). The recent emergence of new races of $P$. striiformis f. tritici adapted to warmer climates increased threats of stripe rust (Chen 2020; Cobo et al. 2018). The use of fungicides can control the disease but many farmers in developing countries cannot afford it. The most efficient way to mitigate stripe rust damages is by breeding for disease resistance. More than 80 officially named $\mathrm{Yr}$ genes have been found in wheat and its close wild relatives (J. Li et al. 2020; McIntosh et al. 2017; Pakeerathan et al. 2019). However, most of these genes were overcome by $P$. striiformis f. tritici shortly after they were deployed in fields. There are two classes of stripe rust resistance genes: all-stage resistance (ASR, also referred as seedling resistance) and adultplant resistance (APR). Even though ASR resistance is more effective and easily transferred, it tends to loss effectiveness within a few years because it is race specific. APR genes are usually not race specific and, therefore, more durable (Chen 2005; Chen et al. 2013). Only a few studies searched for APR quantitative trait loci (QTL) to stripe rust in durum wheat (Lin et al. 2018; Singh et al. 2013; $\mathrm{Xu}$ et al. 2013). Therefore, the durum gene pool may serve as a new source of stripe rust resistance that can be used in breeding both durum and common wheats. Svevo is an Italian durum wheat cultivar released in 1996, and its pedigree is Linea CIMMYT $\times$ Zenit. In 2019, an international consortium generated a highquality reference sequence of the durum wheat cultivar Svevo 
(Maccaferri et al. 2019). The Svevo assembly scaffolds span 10.45 $\mathrm{Gb}$, with $95 \%$ of the scaffolds anchored and $90 \%$ oriented. The physical maps and annotated information of genomes enabled the fine mapping, cloning, and functional analysis of wheat agronomic traits and genes, and accelerated the genetic improvement of cultivated wheat. Preliminary results have indicated that Svevo is highly resistant in all tested environments in both China and Israel. The objectives of this study were to map stripe rust resistance QTL in the Svevo and Zavitan mapping population and to compare the QTL with previously reported stripe rust resistance QTL.

\section{Materials and Methods}

Plant materials. To map the QTL for stripe rust resistance in Svevo, we used a mapping population of a cross between the Italian durum wheat cultivar Svevo and wild emmer wheat (T. dicoccoides) accession Zavitan. In total, $137 \mathrm{~F}_{7}$ recombinant inbred lines (RILs)
A

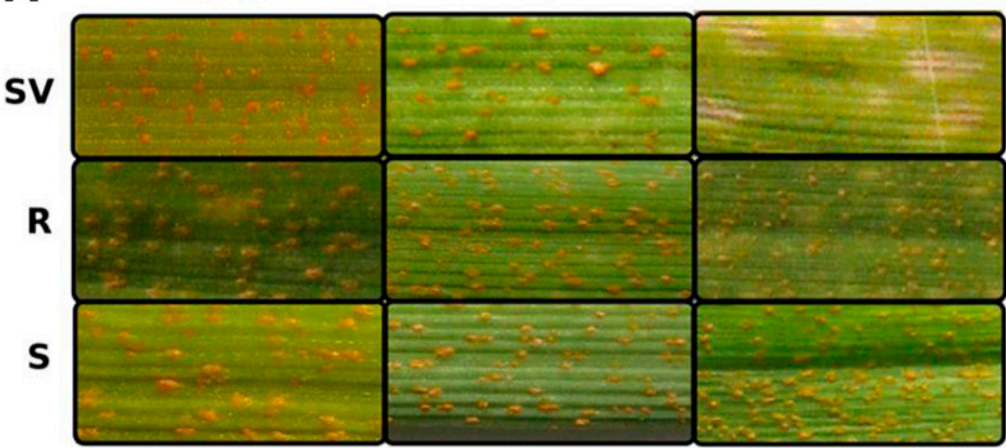

B

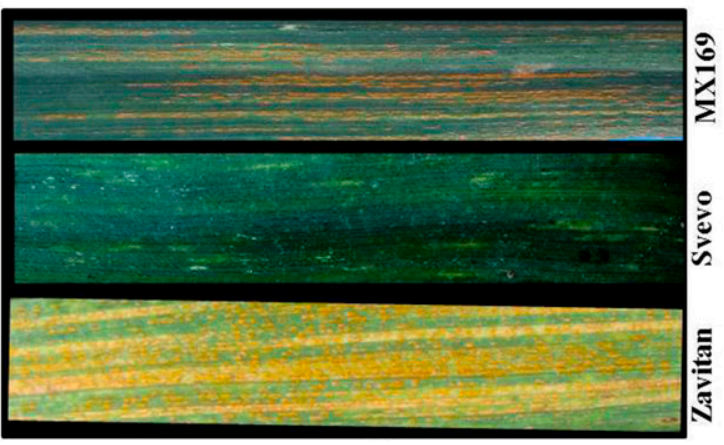

Fig. 1. Stripe rust reactions on seedling at the stages of $A$, one to two, two to three, and four to five leaves of Svevo (SV), resistant (R), and susceptible (S) recombinant inbred lines and B, on flag leaves of Mingxian 169 (MX169), Svevo, and Zavitan.
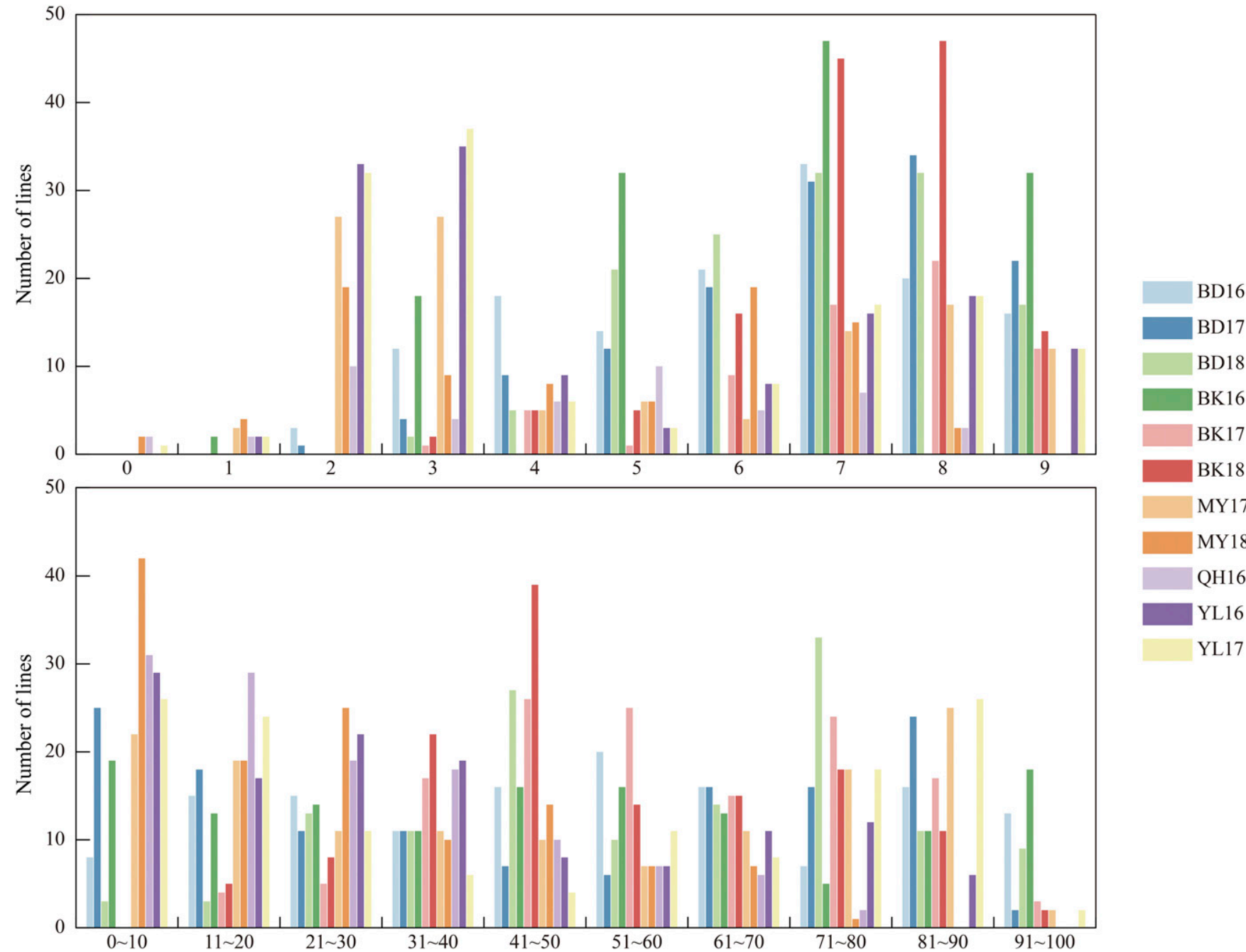

Fig. 2. Frequency distributions of mean infection types (0 to 9$)$ and disease severities ( 0 to 100$)$ for 137 recombinant inbred lines from cross Svevo $\times$ Zavitan grown in China and Israel in 2016 to 2018. 
were developed from Svevo and Zavitan by Avni et al. (2014), using the single-seed descent method. Common wheat cultivars Mingxian 169 (MX169) and Falchetto were used as susceptible controls in stripe rust tests in China and Israel, respectively.

Greenhouse tests. To determine the growth stage at which APR is expressed, susceptible and resistant RILs and Svevo were inoculated at the one-to-two-, two-to-three-, and four-to-five-leaf stages with one Israeli $P$. striiformis f. tritici race, 38E134. Five Chinese $P$. striiformis f. tritici races (CYR29, CYR30, CYR32, CYR33, and CYR34) and one Israeli race (38E134) were used in assessing stripe rust responses of the parents and RILs in the greenhouse. The virulence or avirulence characteristics of these races were previously reported by Zhou et al. (2019) and Cheng et al. (2010). Svevo, Zavitan, MX169, and Falchetto were evaluated at the seedling and adult-plant stages. For seedling tests, 10 to 15 plants of each cultivar or line were grown in a 9-by-9-by-9-cm pot and, for adult-plant tests, three plants were grown in a 20-by-20-by-15-cm pot. Details of inoculation were described previously (Zhou et al. 2015 a,b). Infection types (ITs) were recorded 18 to 21 days after inoculation using a 0 -to- 9 scale (Line and Qayoum 1992). Plants with ITs 0 to 6 were considered resistant and those with ITs 7 to 9 susceptible. All tests were repeated three times.

Field tests. The $\mathrm{F}_{7}$ to $\mathrm{F}_{9}$ RILs and their parents were evaluated for APR to stripe rust in China fields in Yangling of Shaanxi Province in 2016 and 2017 (YL16 and YL17: 34.292 N, 108.077 E), and Huzhu County, Qinghai Province in 2016 (QH16: 36.802 N, 101.962 E), and Mianyang, Sichuan Province in 2017 and 2018 (MY17 and MY18: $31.682 \mathrm{~N}, 104.663 \mathrm{E}$ ); and also in Israel fields in Bet Dagan (BD16, BD17, and BD18: 32.006 N, 34.847 E) and Barkai (BK16, BK17, and BK18: 32.480 N, 35.034 E) in 2016 to 2018. Field trials

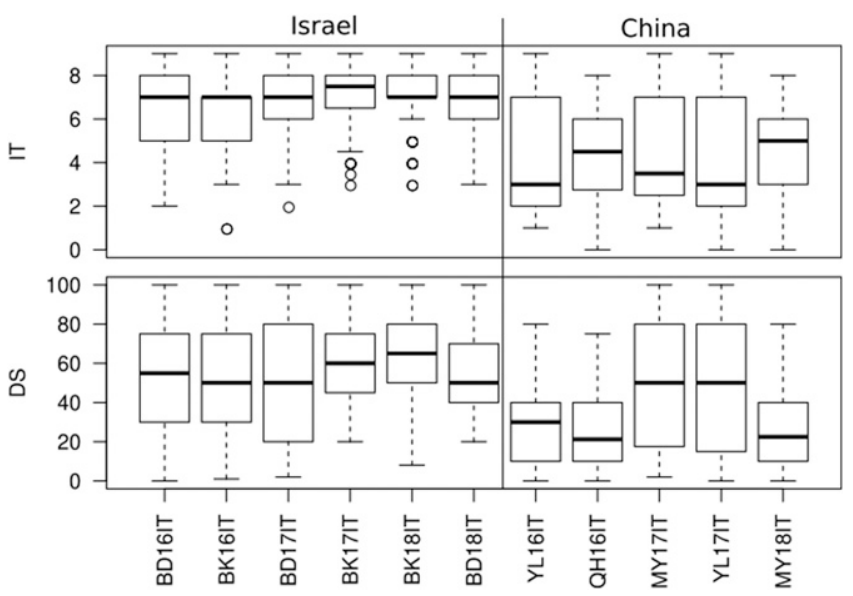

Fig. 3. Stripe rust scores illustrated by the average infection type (IT) and disease severity (DS) of recombinant inbred lines from Svevo $\times$ Zavitan in 11 environments in Israel and China. were conducted in randomized complete blocks, with two replicates at each location. Each plot consisted of a single row, $1.0 \mathrm{~m}$ in length and with $25 \mathrm{~cm}$ between rows. Approximately 25 to 30 seeds were sown in each row. Every 20th row was planted with the highly susceptible controls MX169 in China and Falchetto in Israel. To increase $P$. striiformis f. tritici inoculum, MX169 in China and Falchetto in Israel were planted around the experimental nursery. The field in Yangling, China was artificially inoculated with a mixture of races CYR32 and CYR33 in 2016 and CYR32, CYR33, and CYR34 in 2017 in late March, after the emergence of flag leaves. In the Israeli fields, the susceptible spreader was artificially inoculated with race 38E134 four times from the middle of January to the middle of February. The fields in Mianyang and Huzhu, China were under natural infection because these locations are in the hotspot regions of stripe rust. IT was based on the 0-to-9 scale (Line and Qayoum 1992), and disease severity (DS) of each parent or RIL was scored when the susceptible checks MX169 or Falchetto had $80 \%$ or more DS values from the heading (Z50) and grain filling (Z80) stages (Zadoks et al. 1974). The P. striiformis f. tritici races detected at the Yangling field during the 2016 and 2017 seasons, together with their virulence profiles, were described previously ( $\mathrm{Wu}$ et al. 2016).

Mapping population and the genetic map. The $90 \mathrm{~K}$ singlenucleotide polymorphism (SNP) genotypic data of all 137 lines and their parents and the genetic map were obtained from Avni et al. (2014). The map includes, in total, 14,088 markers binned into 2,296 genetic loci in the 14 chromosomes of tetraploid wheat. Only the skeleton map with one SNP per locus was used. The map is 2,110 centimorgans (cM) long with an average distance of $0.92 \mathrm{cM}$ between adjacent markers. This map facilitated the ordering and the orientation of the scaffolds in the assembly of the Svevo genome (Maccaferri et al. 2019).

Statistical analysis for the phenotypic data. The IT and DS data from each environment were used for the analysis of variance (ANOVA) and subsequent QTL mapping. ANOVA and Pearson's correlation coefficients were performed using the "AOV" tool in software QTL IciMapping V4.1 (Meng et al. 2015; Wang 2009). The information in the ANOVA table was used to calculate heritability in the broad sense $\left(h^{2}\right)$ for stripe rust resistance: $h^{2}=\sigma_{g}^{2} /\left(\sigma_{g}^{2}+\sigma_{g e}^{2} /\right.$ $\left.r+\sigma_{\varepsilon}^{2} / r e\right)$, where $\sigma_{g}^{2}, \sigma_{g e}^{2}$, and $\sigma_{\varepsilon}^{2}$ were estimated values for genotype (line), genotype-environment interaction, and residual error variances, respectively, and $e$ and $r$ were the numbers of environments and replicates per environment.

QTL analysis. QTL analysis was conducted using QTL IciMapping V4.1 (Meng et al. 2015; Wang 2009). Mapping was conducted first using the biparental population (BIP) module and the inclusive composite interval mapping of additive and dominant QTL (ICIM-ADD) model. The mapping parameters were step $=1 \mathrm{cM}$ and probability of SNP to be included in the model (PIN) = 0.0001. The threshold likelihood of odds (LOD) score to declare significant QTL was set to 5.0 for all 14 chromosomes analyzed together. After this, the LOD score was set at 2.5 for each chromosome analysis to declare significant QTL. The walking speed chosen

Table 1. Analysis of variance and estimate of broad-sense heritability of infection type (IT) and disease severity (DS) among recombinant inbred lines from Svevo and Zavitan tested at China and Israel in 2016 to 2018

\begin{tabular}{|c|c|c|c|c|c|c|c|c|}
\hline \multirow[b]{2}{*}{ Source of variation ${ }^{a}$} & \multicolumn{4}{|c|}{$\mathbf{I T}^{\mathbf{b}}$} & \multicolumn{4}{|c|}{$\mathbf{D S}^{\mathbf{b}}$} \\
\hline & Df & MS & $F$ value & $P$ value & Df & MS & $F$ value & $P$ value \\
\hline Line & 136 & 44.71 & 46.54 & $<0.01$ & 136 & $7,258.48$ & 64.31 & $<0.01$ \\
\hline Replicate (environments) & 13 & 5.22 & 5.43 & $<0.01$ & 13 & $1,777.03$ & 15.74 & $<0.01$ \\
\hline Environments & 10 & 372.46 & 387.72 & $<0.01$ & 10 & $62,686.12$ & 555.41 & $<0.01$ \\
\hline Lines $\times$ environments & 1,321 & 4.07 & 4.24 & $<0.01$ & 1,320 & 606.52 & 5.37 & $<0.01$ \\
\hline Error & 1,677 & 0.96 & $\ldots$ & $\ldots$ & 1,678 & 112.86 & $\ldots$ & $\ldots$ \\
\hline$\sigma^{2} g$ & 1.85 & $\ldots$ & $\ldots$ & $\ldots$ & 302.36 & $\ldots$ & $\ldots$ & $\ldots$ \\
\hline$h^{2}$ & 0.91 & $\ldots$ & $\ldots$ & $\ldots$ & 0.92 & $\ldots$ & $\ldots$ & $\ldots$ \\
\hline
\end{tabular}

a Symbols: $\sigma_{g}^{2}$ was estimated for genotypic (line) variances and $h^{2}$ was estimated for heritability in the broad sense on the base of the mean across replications and environments (or heritability per mean).

${ }^{\mathrm{b}} \mathrm{MS}=$ mean square . 
for QTL mapping was $1.0 \mathrm{cM}$, with $P=0.001$ in stepwise regression. The multienvironment (MET) module was used to scan QTL in all environments together. Based on 1,000 permutations at a probability of 0.01 , the percent phenotypic variance explained (PVE) by a single QTL and additive effects at the LOD peaks were determined also using QTL IciMapping. In this module, the ICIM-ADD model and the ICIM epistatic QTL (EPI) model that scans for digenic epistasis QTL were used. The parameters were step $=1 \mathrm{cM}$ and PIN $=0.0001$, and the LOD threshold was determined by 1,000 permutations and type I error level of 0.01. In this study, the genotype of Svevo was defined as A (female) and that of Zavitan as B (male). Because Svevo was resistant and Zavitan was susceptible to stripe rust, the alleles from Svevo reduced stripe rust IT and DS when the additive effect was positive.

Table 2. Summary of stripe rust resistance quantitative trait loci (QTL) identified using the biparental population model based on mean disease severity (DS) and infection type (IT) of the Svevo and Zavitan recombinant inbred line population tested in China and Israel in 2016 to $2018^{a}$

\begin{tabular}{|c|c|c|c|c|c|c|c|}
\hline \multirow{2}{*}{$\begin{array}{l}\text { QTL, } \\
\text { environment }\end{array}$} & \multirow[b]{2}{*}{ Marker } & \multicolumn{3}{|c|}{ IT } & \multicolumn{3}{|c|}{ DS } \\
\hline & & $\overline{\text { LOD }}$ & PVE & $\overline{\text { Add }}$ & LOD & PVE & $\overline{\text { Add }}$ \\
\hline \multicolumn{8}{|c|}{ QYrsv.swust-1AL } \\
\hline BK17 & IWB31650 & 2.67 & 6.81 & 0.34 & 2.77 & 7.31 & 7.48 \\
\hline BK18 & IWB36087 & 2.85 & 7.53 & 0.34 & $\ldots$ & $\ldots$ & $\ldots$ \\
\hline YL17 & $\ldots$ & $\ldots$ & $\ldots$ & $\ldots$ & 2.70 & 7.32 & 7.48 \\
\hline \multicolumn{8}{|l|}{$\begin{array}{l}\text { QYrsv.swust- } \\
\text { 1BL.1 }\end{array}$} \\
\hline BD16 & IWB5732 & 10.54 & 31.44 & 1.09 & 11.02 & 31.54 & 15.93 \\
\hline BK16 & IWB9706 & 9.96 & 30.49 & 1.19 & 7.56 & 23.67 & 14.91 \\
\hline BD17 & $\ldots$ & 11.93 & 34.37 & 1.01 & 7.55 & 24.36 & 15.68 \\
\hline BK17 & $\ldots$ & 7.28 & 22.45 & 0.64 & 5.42 & 17.39 & 8.11 \\
\hline BD18 & $\ldots$ & 7.09 & 22.62 & 0.61 & 3.34 & 11.00 & 7.88 \\
\hline BK18 & $\ldots$ & 4.53 & 15.28 & 0.57 & 6.62 & 21.58 & 9.02 \\
\hline YL16 & $\ldots$ & 4.35 & 15.31 & 0.99 & 4.96 & 18.06 & 9.19 \\
\hline QH16 & $\ldots$ & 3.32 & 13.78 & 0.69 & 3.38 & 13.46 & 6.75 \\
\hline MY17 & $\ldots$ & 5.12 & 17.33 & 1.05 & 8.20 & 25.90 & 16.32 \\
\hline YL17 & $\ldots$ & 5.57 & 18.36 & 1.12 & 8.27 & 25.87 & 16.96 \\
\hline MY18 & $\ldots$ & 4.93 & 18.91 & 0.85 & 5.29 & 19.28 & 8.51 \\
\hline \multicolumn{8}{|l|}{$\begin{array}{l}\text { QYrsv.swust- } \\
\text { 1BL.2 }\end{array}$} \\
\hline \multirow[t]{2}{*}{ DB16 } & $I W B 11625$ & 4.71 & 12.35 & 0.62 & $\ldots$ & $\ldots$ & $\ldots$ \\
\hline & IWA3497 & $\ldots$ & $\ldots$ & $\ldots$ & $\ldots$ & $\ldots$ & $\ldots$ \\
\hline \multicolumn{8}{|c|}{ QYrzv.swust-2AS } \\
\hline BD16 & IWB7877 & 2.69 & 8.65 & -0.57 & 2.84 & 9.02 & -9.48 \\
\hline BK17 & $I W B 72720$ & 2.91 & 8.72 & -0.42 & $\ldots$ & $\ldots$ & $\ldots$ \\
\hline BD18 & $\ldots$ & $\ldots$ & $\ldots$ & $\ldots$ & 2.87 & 9.27 & -6.06 \\
\hline \multicolumn{8}{|c|}{ QYrsv.swust-2BS } \\
\hline \multirow[t]{2}{*}{ YL17 } & IWB32200 & 4.47 & 13.79 & 0.92 & $\ldots$ & $\ldots$ & $\ldots$ \\
\hline & IWB22938 & $\ldots$ & $\ldots$ & $\ldots$ & $\ldots$ & $\ldots$ & $\ldots$ \\
\hline \multicolumn{8}{|c|}{ QYrsv.swust-3AS } \\
\hline BK16 & IWB7237 & 4.06 & 9.38 & 0.63 & $\cdots$ & $\ldots$ & $\ldots$ \\
\hline BD16 & IWB8523 & $\ldots$ & $\ldots$ & $\ldots$ & 2.64 & 4.64 & 6.75 \\
\hline BD17 & $\ldots$ & 5.14 & 11.62 & 0.55 & $\ldots$ & $\ldots$ & $\ldots$ \\
\hline \multicolumn{8}{|c|}{ QYrsv.swust- $4 A L$} \\
\hline BD17 & IWB11158 & $\ldots$ & $\ldots$ & $\ldots$ & 3.32 & 11.33 & 10.42 \\
\hline YL16 & IWB36731 & 2.92 & 9.71 & 0.79 & $\ldots$ & $\ldots$ & $\ldots$ \\
\hline MY17 & $\ldots$ & 3.37 & 11.08 & 0.84 & 3.90 & 13.06 & 11.30 \\
\hline YL17 & $\ldots$ & 3.62 & 11.80 & 0.89 & 4.25 & 14.02 & 12.18 \\
\hline \multicolumn{8}{|l|}{$\begin{array}{l}\text { QYrsv.swust- } \\
5 A L .1\end{array}$} \\
\hline BK16 & IWA5118 & 3.05 & 6.16 & 0.52 & $\ldots$ & $\ldots$ & $\ldots$ \\
\hline BK17 & IWB60872 & 4.20 & 8.52 & 0.43 & $\ldots$ & $\ldots$ & $\ldots$ \\
\hline BK18 & $\ldots$ & 2.93 & 6.28 & 0.36 & $\ldots$ & $\ldots$ & $\ldots$ \\
\hline \multicolumn{8}{|l|}{$\begin{array}{l}\text { QYrsv.swust- } \\
\text { 5AL.2 }\end{array}$} \\
\hline QH16 & IWB71794 & 3.47 & 11.89 & 0.64 & 3.36 & 11.79 & 6.19 \\
\hline MY18 & $I W B 71147$ & 3.01 & 7.53 & 0.55 & 3.20 & 7.15 & 5.89 \\
\hline
\end{tabular}

${ }^{\mathrm{a}}$ Marker $=$ marker interval, LOD $=$ logarithm of odds score, $\mathrm{PVE}=$ percentage of the phenotypic variance explained by individual QTL, and Add = additive effect of resistance allele.
To determine the additive effects of the QTL, the effects of QTL combinations were demonstrated by plotting boxplots for mean IT and mean DS of the RILs sharing the same number of beneficial alleles.

Comparison of 1B QTL with previous reported QTL. To compare the QTL identified in this study with previously published $P$. striiformis f. tritici resistance genes and QTL, and to obtain physical positions, the reference sequence and marker alignments of polymorphic SNP markers and the SNP probes were aligned with the Chinese Spring sequence through a BLAST search (IWGSC RefSeq v1.0; https://plants.ensembl.org/Triticum_aestivum/Info/ Index; CS genome hereafter). The SNP probes were also blasted against the Svevo genome sequences at the GrainGenes Svevo Genome Browser (Durum Wheat Svevo RefSeq Rel. 1.0; https://wheat.pw.usda.gov/GG3/genome_browser; durum genome hereafter).

\section{Results}

Phenotypic evaluation. Seedling tests with plants of susceptible and resistant RILs and of Svevo inoculated at different stages with the Israeli race (38E134) showed that plants were susceptible before the four-leaf stage but plants at the five-leaf stage began to show stripe rust resistance. Svevo at the five-leaf stage had IT 3 to 4, which was much lower than the IT of the most resistant RIL (Fig. 1A). To determine the broadness of the resistance in Svevo, six P. striiformis f. tritici races were used to inoculate Svevo together with susceptible control cultivars Zavitan, Falchetto, and MX169. The results showed that Svevo was susceptible (IT 8 to 9) to all six races (one from Israel and five from China) in the seedling tests but highly resistant (IT 1) in the adult-plant tests to all races. The susceptible parent, Zavitan, and MX169 and Falchetto were susceptible (IT 8 to 9) at both growth stages. Svevo had consistent IT 1 in the adult-plant stage under field conditions, whereas Zavitan, MX169, and Falchetto displayed IT 9 in all environments with a severity of 90 to $100 \%$ (Fig. 1B). The IT and DS values of the 137 RILs were in the range of 0 to 9 and 0 to $100 \%$, respectively, indicating that resistance was quantitatively inherited (Fig. 2). In general, the ITs in Israel were higher for most of the lines than the ITs in China (Fig. 3). The broad-sense heritability of IT and DS was 0.91 and 0.92 , respectively. Correlation coefficients $(r)$ between IT and DS varied greatly between the 11 environments $(r=$ 0.36 to 0.98 ) (Supplementary Table S1). The correlation coefficients were higher between the environments in China or in Israel but lower between environments in the two countries. In the pairwise comparison of the IT or DS, the values of $r$ were all significant $(P<0.001)$ (Table 1), although the values of $r$ between years were slightly lower than that within years. The ANOVA results based on both the IT and DS data showed that the interactions among the RILs, environments, and line-environment were significant $(P<0.01)$ (Table 2). No significant variation was detected among replications within each experiment, and the lines were the main source of high-heritability phenotypic variation.

QTL analysis of stripe rust resistance. QTL for stripe rust resistance were scanned through all 14 chromosomes by the ICIM method implemented in software Ici-Mapping V4.1. Nine QTL were discovered using the BIP and MET methods (Tables 2 and 3; Figs. 4 and 5). The designated QTL were those significant for both IT and DS and with the highest peak in a 5.0-cM region using the MET method. The most significant QTL was found on the long arm of chromosome 1B (125 cM) and was designated QYrsv.swust-1BL.1. Based on the MET analysis, it had a PVE value of 21.17 and $18.49 \%$ for DS and IT, respectively, across all 11 environments. It had DS_LOD (AbyE) 5.9 and IT_LOD (AbyE) 15.8 by environmental interactions. Based on the BIP analysis, QYrsv.swust-1BL.1 was the only stable QTL that was significant for all 11 environments for both IT and DS $(P<0.05$, LOD $>3.0)$, with PVE in the range of 13.8 to $34.4 \%$ for IT and 11.0 to $31.5 \%$ for DS. QYrsv.swust-1BL.1 was derived from Svevo. The other eight QTL had relatively minor effects. QYrsv.swust-1AL (DS_LOD $=20.0$, DS_PVE $=4.32$, IT_LOD $=$ 15.0, IT_PVE $=3.49,88 \mathrm{cM}$ ) explained 6.8 to 7.5 and $7.3 \%$ of phenotypic variation in IT and DS, respectively, in two environments in 
Israel and one environment in China in the BIP analysis. QYrsv. swust-1BL.2 (DS_LOD $=19.6$, DS_PVE $=3.25$, IT_LOD $=22.1$, IT_PVE $=3.73,94 \mathrm{cM}$ ) had $12.35 \%$ PVE for IT in only one environment in Israel in the BIP analysis. QYrzv.swust-2AS (DS_LOD = 11.9, DS_PVE $=3.86$, IT_LOD $=14.1$, IT_PVE $=2.90,10 \mathrm{cM}$ ) was the only one from Zavitan. It was significant in the BIP analysis in only three Israeli environments with PVE values of 8.65 to 8.72 and $9.27 \%$ for IT and DS, respectively. QYrsv.swust-2BS (DS_ $\mathrm{LOD}=20.7, \mathrm{DS} \_\mathrm{PVE}=3.46, \mathrm{IT} \_\mathrm{LOD}=21.5, \mathrm{IT} \_\mathrm{PVE}=2.13, \overline{3}$ $\mathrm{cM}$ ) had $13.79 \%$ PVE for IT in only one environment in China in the BIP analysis. QYrsv.swust-3AS (DS_LOD $=15.5$, DS_PVE $=$ 3.02 , IT_LOD $=22.6$, IT_PVE $=3.30,20 \mathrm{cM}$ ) had PVE values of 9.38 to 11.62 and $4.64 \%$ for IT and DS, respectively, in three Israeli environments in the BIP analysis. This QTL was not significant for DS in the 1,000 permutation test of the MET analysis. However, the LOD score for DS was still high (15.5 and 19.4 for DS and IT, respectively). QYrsv.swust-4AL (DS_LOD $=15.2$, DS_PVE = 4.60, IT_LOD $=11.6$, IT_PVE $=4.25,127 \mathrm{cM}$ ) explained 9.71 to 11.8 and 11.33 to $14.02 \%$ of phenotypic variation in IT and DS, respectively, in one environment in Israel and three environments in China in the BIP analysis. QYrsv.swust-5AL.1 (DS_LOD $=13.8$, DS_PVE $=2.10$, IT_LOD $=14$, IT_PVE $=1.93,85 \mathrm{cM}$ ) explained 6.16 to $8.52 \%$ of phenotypic variation in IT in three environments in Israel in the BIP analysis. QYrsv.swust-5AL.2 (DS_LOD $=16.7$, DS_PVE $=3.81$, IT_LOD $=19.3$, IT_PVE $=3.88,166 \mathrm{cM}$ ) explained 7.53 to 11.89 and 7.15 to $11.79 \%$ of phenotypic variation in IT and DS, respectively, in two environments in China in the BIP analysis.

Digenic epistatic QTL. The scan for digenic epistatic QTL using the ICIM-EPI function in the MET analysis resulted in 99 marker pairs with LOD scores above 10, of which 13 pairs had LOD scores greater than 20 . Only 2 of the $2 \times 13$ markers were located near a monogenic QTL (Table 4).

Additive interactions between detected resistance loci. To visualize the individual and combined effects of the nine QTL on IT and DS, we used the alleles at each QTL peak marker to group RILs with the same number of beneficial allele numbers and to obtain their means across the 11 environments (Fig. 6). There were significant additive effects for stripe rust resistance where more beneficial alleles resulted in lower IT and DS. We have also tested each combination of the alleles in all RIL lines. The best combination was when all alleles from Svevo were present without the 2AL QTL from Zavitan (one RIL, IT = 2.7). However, a combination of only four QTL $(2 \mathrm{AL}+$ 1BL. $1+1$ BL. $2+2 B S$ ) resulted in IT of 2.9 (one RIL). None of the combinations was more resistant than Svevo or more susceptible than Zavitan.

The QYr.swust-1BL.1 region. Based on the results presented in Figure 5-1B1, QYr.swust-1BL.1 was mapped in the region containing markers IWB5732, IWB4839, IWB9706, and IWB3447I $(0.75 \mathrm{cM})$ of the consensus 90K SNP map (Avni et al. 2014; Maccaferri et al. 2015a,b; Wang et al. 2014). The sequences of all closely linked polymorphic SNPs were blasted against the CS genome and the Svevo genome to determine their physical positions. This region was physically mapped to the region between the 661,593,905 bp (IWB5732) and $663,334,619$ bp (IWB4839) positions of $1.7 \mathrm{Mb}$ in the durum 1BL chromosome and between 670,783,574 bp (IWB5732) and $671,505,487 \mathrm{bp}$ (IWB4839) (721.8 kb) in the CS 1BL chromosome. The $1.7-\mathrm{Mb}$ and $721.8-\mathrm{kb}$ intervals between markers IWB5732 and IWB4839 include 30 and 14 annotated genes in the durum genome and CS genome, respectively (IWGSC RefSeq v1.0; Durum Wheat Svevo RefSeq Rel. 1.0) (Supplementary Table S2).

\section{Discussion}

In order to cope with the continuous variation of $P$. striiformis $\mathrm{f}$. tritici races, it is important to discover new resistant sources and identify new genes. In the present study, we identified QTL for APR to stripe rust in durum wheat cultivar Svevo. Svevo was highly resistant to stripe rust in field environments over several years in Israel and China. The study took advantage of a mapping population of 137 RILs previously developed from a cross between Svevo and wild emmer wheat accession Zavitan and genotyped using the wheat $90 \mathrm{~K}$ SNP array (Avni et al. 2014). The RILs were evaluated for responses to stripe rust in multiple environments. One major QTL (named QYrsv.swust-1BL.1) and eight minor QTL were identified through QTL analysis using the phenotypic data of 11 field environments. The APR locus QYrsv.swust-1BL.1 is effective against the P. striiformis f. tritici populations in both China and Israel.

QYrsv.swust-1AL, mapped on chromosome 1AL, was derived from resistant parent Svevo. It was located in the interval of SNP markers IWB31650 and IWB36087 and was mapped between $531,338,723$ and $591,618,146$ bp of the durum wheat Svevo RefSeq Rel. 1.0, corresponding to the region from 540,051,730 to $597,449,394$ bp of the CS IWGSC RefSeq v1.0 1AL chromosome physical map. To date, nine QTL or genes for stripe rust resistance have been reported on chromosome 1AL by biparental populations and genome-wide association studies (GWAS) (Supplementary Table S3). Among these genes or QTL, QYrww.wgp.1A-3, which was mapped around 540,182,142 bp of durum wheat Svevo RefSeq

Table 3. Summary of nine stripe rust resistance quantitative trait loci (QTL) discovered using the multienvironment analysis based on mean disease severity (DS) and infection type (IT) of the Svevo and Zavitan recombinant inbred line population tested in China and Israel in 2016 to $2018^{\mathrm{a}}$

\begin{tabular}{|c|c|c|c|c|c|c|c|c|c|c|c|c|c|c|c|}
\hline QTL & $\begin{array}{l}\text { Pos } \\
\text { (cM) }\end{array}$ & $\begin{array}{c}\text { Left } \\
\text { marker }\end{array}$ & $\begin{array}{l}\text { Right } \\
\text { marker }\end{array}$ & $\begin{array}{c}\text { LOD } \\
\text { DS }\end{array}$ & $\begin{array}{l}\text { LOD } \\
\text { (A) DS }\end{array}$ & $\begin{array}{c}\text { LOD } \\
\text { (AbyE) DS }\end{array}$ & $\begin{array}{c}\text { PVE } \\
\text { DS }\end{array}$ & $\begin{array}{l}\text { Add } \\
\text { DS }\end{array}$ & $\begin{array}{c}\text { LOD } \\
\text { IT }\end{array}$ & $\begin{array}{l}\text { LOD } \\
\text { (A) IT }\end{array}$ & $\begin{array}{c}\text { LOD } \\
\text { (AbyE) IT }\end{array}$ & $\begin{array}{l}\text { PVE } \\
\text { IT }\end{array}$ & $\begin{array}{c}\text { Add } \\
\text { IT }\end{array}$ & $\begin{array}{c}\text { Left } \\
\text { CI }\end{array}$ & $\begin{array}{c}\text { Right } \\
\text { CI }\end{array}$ \\
\hline $\begin{array}{l}\text { QYrsv.swust- } \\
\quad \text { IAL }\end{array}$ & 88 & $I W B 31650$ & IWB36087 & 20.0 & 18.9 & 1.1 & 4.32 & 5.04 & 15.0 & 12.3 & 2.7 & 3.49 & 0.32 & 87.5 & 88.5 \\
\hline $\begin{array}{l}\text { QYrsv.swust- } \\
\text { lBL.1 }\end{array}$ & 94 & $I W B 11625$ & IWA3497 & 19.6 & 19.0 & 0.7 & 3.25 & 5.07 & 22.1 & 19.7 & 2.4 & 3.73 & 0.40 & 93.5 & 94.5 \\
\hline $\begin{array}{l}\text { QYrsv.swust- } \\
\text { 1BL.2 }\end{array}$ & 125 & IWB5732 & IWB9706 & 61.7 & 55.8 & 5.9 & 21.17 & 9.58 & 70.2 & 54.4 & 15.8 & 18.49 & 0.74 & 124.5 & 125.5 \\
\hline $\begin{array}{l}\text { QYrsv.swust- } \\
2 A S\end{array}$ & 10 & IWB7877 & $I W B 72720$ & 11.9 & 9.9 & 2.0 & 3.86 & -3.66 & 14.1 & 12.2 & 1.9 & 2.90 & -0.31 & 8.5 & 12.5 \\
\hline $\begin{array}{l}\text { QYrsv.swust- } \\
2 B S\end{array}$ & 3 & IWB32200 & IWB22938 & 20.7 & 19.0 & 1.7 & 3.46 & 5.08 & 21.5 & 20.7 & 0.8 & 2.13 & 0.41 & 0 & 4.5 \\
\hline $\begin{array}{l}\text { QYrsv.swust- } \\
3 A S\end{array}$ & 20 & $I W B 7237$ & IWB8523 & 15.5 & 14.2 & 1.3 & 3.02 & 4.32 & 22.6 & 19.4 & 3.2 & 3.30 & 0.39 & 17.5 & 21.5 \\
\hline $\begin{array}{l}\text { QYrsv.swust- } \\
4 A L\end{array}$ & 127 & $I W B 11158$ & IWB36731 & 15.2 & 13.0 & 2.3 & 4.60 & 4.26 & 11.6 & 10.8 & 0.9 & 4.25 & 0.30 & 125.5 & 127.5 \\
\hline $\begin{array}{l}\text { QYrsv.swust- } \\
\text { 5AL.1 }\end{array}$ & 85 & IWA5118 & IWB60872 & 13.8 & 12.7 & 1.2 & 2.10 & 4.29 & 14.0 & 11.0 & 2.9 & 1.93 & 0.31 & 83.5 & 86.5 \\
\hline $\begin{array}{l}\text { QYrsv.swust- } \\
\text { 5AL.2 }\end{array}$ & 166 & $I W B 71794$ & $I W B 71147$ & 16.7 & 15.6 & 1.0 & 3.81 & 4.60 & 19.3 & 17.1 & 2.1 & 3.88 & 0.37 & 165.5 & 166.5 \\
\hline
\end{tabular}

${ }^{a}$ Pos = position in centimorgans $(\mathrm{cM}), \mathrm{LOD}=$ likelihood of odds score for all effects, $\mathrm{LOD}(\mathrm{A})=\mathrm{LOD}$ score for additive and dominance effects, $\mathrm{LOD}(\mathrm{AbyE})=$ LOD score for additive and dominance by environment effects, $\mathrm{PVE}=$ percentage of the phenotypic variance explained by individual QTL, and Add $=$ additive effect of resistance allele. 
Rel. 1.0, overlaps with QYrsv.swust-1AL; however, allelism testing is needed to determine the relationship between $Q Y r w w . w g p .1 A-3$ and QYrsv.swust-1AL. Based on the marker positions of QYrsv.swust$1 A L$ and another eight reported QTL or genes in the genome of durum wheat Svevo RefSeq Rel. 1.0 and CS IWGSC RefSeq v1.0, QYrsv.swust-1AL is different from the eight QTL.

Both QYrsv.swust-1BL.1 and QYrsv.swust-1BL.2 were mapped to the long arm of chromosome $1 \mathrm{~B}$ and consistently associated with APR to stripe rust in multiple environments. QYrsv.swust-1BL.1 was the largest effect QTL that explained 11.0 to $34.4 \%$ of the phenotypic variation for IT and DS, respectively, across all environments in China and Israel. The large effect of this QTL makes it useful for breeding wheat cultivars with adequate resistance to stripe rust. QYrsv.swust-1BL. 1 was located between markers IWB5732 and IWB4839 in the region of $661,593,905$ to $663,334,619$ bp of the durum wheat Svevo RefSeq Rel. 1.0, corresponding to the 670,171,058- to 670,998,484-bp region of the CS 1BL chromosome. QYrsv.swust-1BL.2 was located between markers IWB11625 and IWA3497 in the 556,239,805- to 556,896,247-bp region of the durum genome, corresponding to the $638,931,988$ - to $640,158,195$-bp region of the CS 1BL chromosome. Thus far, more than 20 QTL or genes for stripe rust resistance have been reported on chromosome 1BL using biparental populations and GWAS analysis (Supplementary Table S3). The physical interval of QYrsv.swust-1BL.1

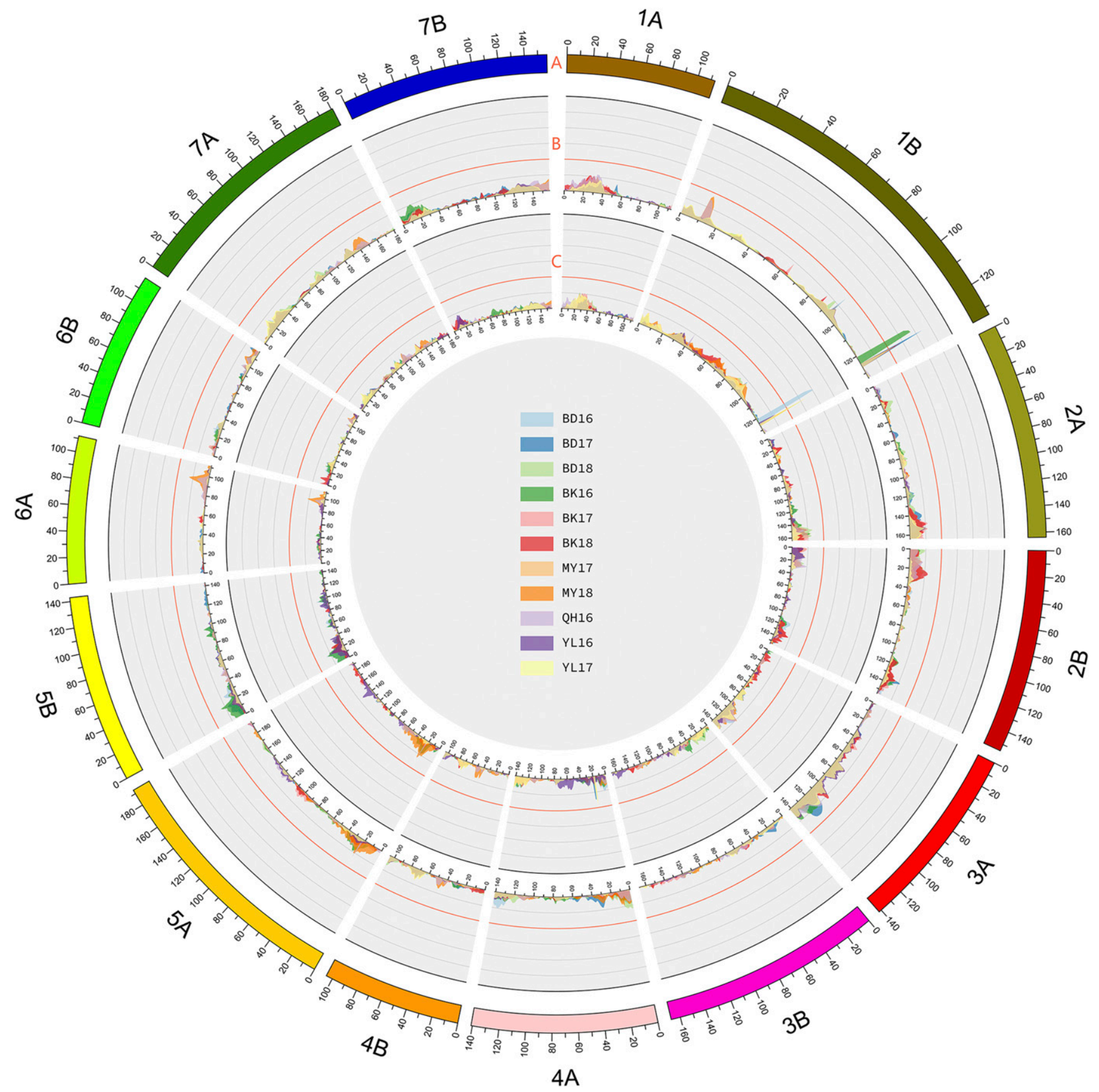

Fig. 4. Circos diagram showing stripe rust resistance quantitative trait loci detected by the biparental population analysis in the Svevo and Zavitan recombinant inbred line populations across 11 environments based on mean infection type (IT) and mean disease severity (DS). Track A: Chromosomes with genetic distance scale (unit: centimorgan). Track B: Likelihood of odds (LOD) values for 11 IT traits on genetic maps of 14 durum wheat chromosomes. Track C: LOD values for 11 DS traits on genetic maps of 14 durum wheat chromosomes. Different shades represent different sites and years of field trials in China and Israel. BD16 = Bet Dagan in 2016, BD17 = Bet Dagan in 2017, BD18 = Bet Dagan in 2018, BK16 = Barkai in 2016, BK17 = Barkai in 2017, BK18 = Barkai in 2018, MY17 = Mianyang in 2017, MY18 = Mianyang in 2018, QH16 = Qinghai in 2016, YL16 = Yangling in 2016, and YL17 = Yangling in 2017. 
overlapped with $\operatorname{Yr} 29$ (William et al. 2003), QYr.ucw-1BL (Cobo et al. 2018), and QYr.saas-1B (Yang et al. 2019). Cobo et al. (2019) mapped QYr.ucw-1BL within a $0.24-\mathrm{cM}$ region (332 kb in the CS genome) on chromosome arm 1BL. The physical region is 669 to $670 \mathrm{Mb}$ in the CS genome. This region overlaps with the location of APR gene Yr29 in the distal region of chromosome arm $1 \mathrm{BL}$ between simple-sequence repeat (SSR) markers Xwmc44 and Xgwm140 (McIntosh et al. 2013). These two markers define a region of $22.7 \mathrm{Mb}$ (between 662.2 and $684.9 \mathrm{Mb}$ in the $\mathrm{CS}$ genome).
Because of no recombination between QYr.ucw- $1 B L$ and $Y r 29$ in an allelism test and similar levels of resistance, Cobo et al. (2019) suggested that QYr.ucw-1BL and Yr29 might be the same gene. The cleaved amplified polymorphic sequence marker cslv46G22 linked to $\operatorname{Yr} 29$ (E. Lagudah, personal communication) is located at the 670.23-Mb position in the CS genome, which is within the QYrsv.swust-1BL.1 physical interval. This marker is present in Svevo. $Y r 29$ is a durable pleiotropic gene ( $\mathrm{rr} 29 / \mathrm{Lr} 46 / \mathrm{Sr} 58 / \mathrm{Pm} 39 /$ $L t n 2)$ for resistance to multiple diseases and leaf tip necrosis and
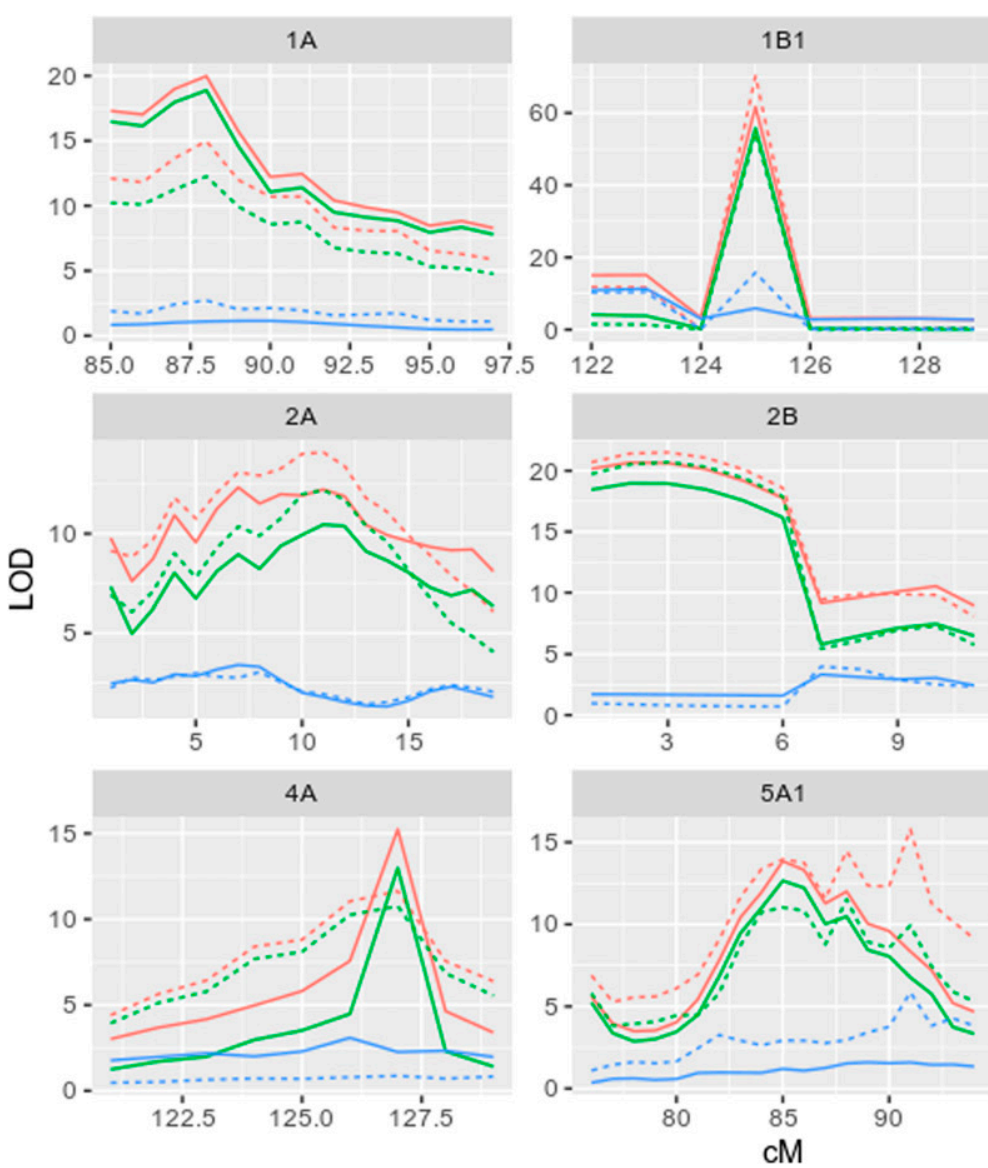
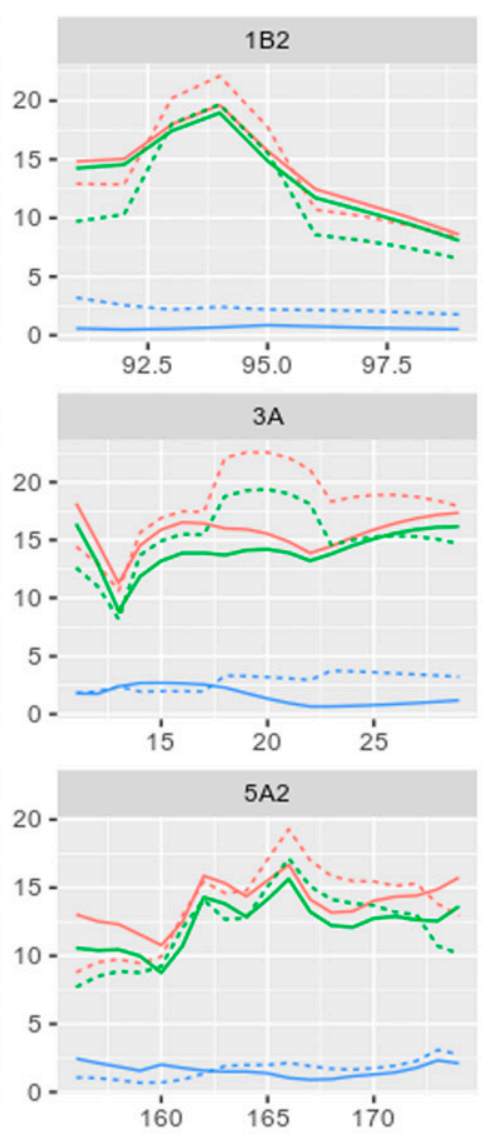

LOD component

- LOD

- LOD_A

- LOD_AbyE

Trait

- DS

… IT

Fig. 5. Likelihood of odds (LOD) scores of the multienvironment analysis on infection type (IT) and disease severity (DS) values in stripe rust resistance quantitative trait loci. LOD = the total $L O D$ score, $L O D \_A=$ the additive effect component of the LOD, LOD_AbyE = the environmental-additive effect component of the $L O D$, and $c M=$ centimorgans. The $X$ axis represents the genetic distance of the chromosomes. The Y-axis represents the threshold LOD score. $1 \mathrm{~A}=$ QYrsv.swust-1AL, $1 \mathrm{~B} 1=\mathrm{QY}$ rsv.swust-1BL.1, 1B2 $=$ QYrsv.swust1BL.2, 2A = QYrzv.swust-2AS, 2B = QYrsv.swust-2BS, 3A = QYrsv.swust-3AS, 4A = QYrsv.swust-4AL, 5A1 = QYrsv.swust-5AL.1, and 5A2 = QYrsv.swust-5AL.2.

Table 4. Digenic epistasis of quantitative trait loci using the inclusive composite interval mapping epistatic quantitative trait loci analysis based on infection type of the Svevo and Zavitan recombinant inbred line population tested in China and Israel in 2016 to $2018^{\mathrm{a}}$

\begin{tabular}{|c|c|c|c|c|c|c|c|c|}
\hline \multirow[b]{2}{*}{ Chr 1} & \multirow[b]{2}{*}{ Pos 1} & \multicolumn{2}{|c|}{ Marker 1} & \multirow[b]{2}{*}{ Chr 2} & \multirow[b]{2}{*}{ Pos 2} & \multicolumn{2}{|c|}{ Marker 2} & \multirow[b]{2}{*}{ LOD } \\
\hline & & Left & Right & & & Left & Right & \\
\hline $3 B$ & 25 & IWB56976 & $I W B 37668$ & $4 \mathrm{~B}$ & 35 & $I W B 73540$ & IWB19555 & 27.5946 \\
\hline $5 \mathrm{~A}$ & 105 & IWB34534 & IWB63277 & $2 \mathrm{~B}$ & 10 & IWB48447 & IWB51601 & 27.583 \\
\hline $1 \mathrm{~A}$ & 75 & IWB38172 & IWB9711 & $3 \mathrm{~A}$ & 130 & IWB2639 & $I W B 72476$ & 25.3832 \\
\hline $2 \mathrm{~A}$ & 30 & IWB18255 & IWB20411 & $3 \mathrm{~A}$ & 50 & IWB43537 & $I W B 25733$ & 24.6525 \\
\hline $3 \mathrm{~A}$ & 5 & IWB73673 & IWB16449 & $3 \mathrm{~A}$ & 110 & IWB12566 & IWA5015 & 24.6266 \\
\hline $7 \mathrm{~A}$ & 135 & IWA3562 & IWB7382 & 1B & 5 & IWB16597 & IWB16421 & 23.6251 \\
\hline $2 \mathrm{~A}$ & 20 & IWB6982 & $I W B 72370$ & $5 \mathrm{~B}$ & 150 & IWB47086 & IWA3285 & 23.3507 \\
\hline $1 \mathrm{~A}$ & 75 & IWB38172 & IWB9711 & $1 \mathrm{~A}$ & 85 & $I W B 20654$ & $I W B 26829$ & 23.0006 \\
\hline $6 \mathrm{~A}$ & 50 & IWB15805 & $I W B 74347$ & $6 \mathrm{~A}$ & 65 & $I W B 7681$ & IWB7281 & 22.6635 \\
\hline $6 \mathrm{~A}$ & 40 & IWB72590 & $I W B 4117$ & $4 \mathrm{~B}$ & 55 & IWB73477 & IWB11687 & 22.5769 \\
\hline $6 \mathrm{~A}$ & 45 & IWB67076 & IWB68716 & $6 \mathrm{~B}$ & 80 & IWB45911 & $I W B 23748$ & 21.5555 \\
\hline $7 \mathrm{~A}$ & 15 & IWB19538 & IWB57104 & $7 \mathrm{~B}$ & 145 & IWB63507 & IWB6574 & 21.1244 \\
\hline $2 \mathrm{~A}$ & 110 & IWB32349 & IWB52020 & $4 B$ & 65 & IWB35851 & IWB73999 & 20.3344 \\
\hline
\end{tabular}

${ }^{\mathrm{a}} \mathrm{Chr}=$ chromosome, Pos $=$ position, and LOD $=$ likelihood of odds score for all effects. 
has been reported in many hexaploid and durum wheat genotypes and associated with necrotic leaf tips (Herrera-Foessel et al. 2011; Kolmer 2015; Lan et al. 2015, 2019; H. Y. Li et al. 2020; PonceMolina et al. 2018). However, Svevo does not show leaf tip necrosis. QYr.saas- $1 B$ was identified in common wheat genotype $\mathrm{CH} 55$ with the $1 \mathrm{RS} / 1 \mathrm{BL}$ translocation, explaining 6.24 to $34.22 \%$ of the stripe rust phenotypic variation in all tested environments (Yang et al. 2019). It was physically located between 664.08 and $673.64 \mathrm{Mbp}$ in the CS genome, also overlapping with Yr29. Yang et al. (2019) concluded that Qyr.saas-1B was most likely $\operatorname{Yr} 29$. More work is needed to determine whether QYrsv.swust-1BL.1, Yr29, and Qyr.saas-1B are identical, allelic, or closely linked.

QYrzv.swust-2AS flanked by IWB7877 and IWB72720 is derived from Zavitan. It explained 8.7 to $9.3 \%$ of the phenotypic variation in three Israeli environments. It was also significant in the MET analysis but with a low LOD due to the additive-environment effect (LOD_AbyE). An RIL having the Zavitan allele of this QTL with three additional beneficial alleles from Svevo was ranked the third most resistant RIL across all environments (mean IT 2.9). The QYrzv.swust-2AS region corresponds to the CS physical map region between 5,246,322 and 5,329,931 bp. Three permanently named stripe rust resistance genes-Yrl7 (Helguera et al. 2003), Yr56 (Bansal et al. 2014), and $\operatorname{Yr69}$ (Hou et al. 2016) —have been mapped to 2AS. Because $\operatorname{Yr} 17$ and $\operatorname{Yr} 69$ confer ASR, neither of these genes can be identical to QYrzv.swust-2AS associated with minor-effect APR. Yr56 is an APR gene mapped between markers Xsun167 and Xsun168 in Australian durum wheat variety Wollaroi (Bansal et al. 2014; McIntosh et al. 2013). Thus far, at least 20 stripe rust resistance QTL have been reported on chromosome 2AS, and most of them are located at the distal end of 2AS (Supplementary Table S3). According to the source of resistance and the molecular markers linked to the corresponding QTL loci, the QTL identified in the present study is unlikely to be the previously reported QTL.

QYrsv.swust-2BS from Svevo was located between the SNP markers IWB32200 and IWB22938 on chromosome 2BS. This QTL was mapped between 2,559,330 and 5,322,733 bp on chromosome $2 \mathrm{~B}$ of the durum genome, corresponding to the region from $2,478,547$ to $6,263,146$ bp of CS 2BS. Thus far, more than 30 genes or QTL have been reported on chromosome 2BS using biparental populations and GWAS analysis (Supplementary Table S3). Based on the physical positions in the durum genome, some loci of genes or QTL are different from QYrsv.swust-2BS. The relationships between QYrsv.swust-2BS and the previously reported genes or QTL in the chromosomal region need to be further studied.

QYrsv.swust-3AS was mapped between markers IWB7237 and IWB8523 on the short arm of chromosome $3 \mathrm{~A}$ and in the $21,260,083$ - to $22,479,098$-bp region of chromosome $3 \mathrm{~A}$ of the durum genome, corresponding to the $24,748,734$ - to $25,946,889$ bp region of CS chromosome 3AS. Thus far, only one formally named $\mathrm{Yr}$ gene, $\mathrm{Yr} 76$, has been reported on chromosome 3AS. Yr76 originated from soft winter club wheat cultivar Tyee, and

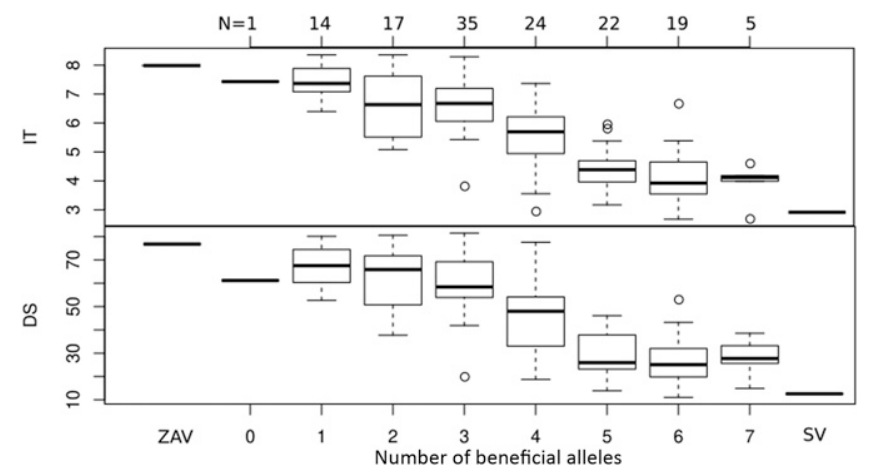

Fig. 6. Distribution of infection type (IT) and disease severity (DS) values of recombinant inbred lines (RILs) grouped by their number of beneficial alleles from nine quantitative trait loci. The upper scale denotes the number of RILs in each group. confers ASR to some $P$. striiformis f. tritici races (Xiang et al. 2016). $Y r H u$ is located between $X c f d 79(7.2 \mathrm{cM})$ and $X B G 604577$ $(0.7 \mathrm{cM})$ in the short arm of 3AS (Ma et al. 2016). Yrq2 was mapped in Chinese cultivar Xichang 76-9 and was linked with SSR markers Xwmc11 and Xbarc57 (Cao et al. 2012). The Yrq2 region may overlap with $Y r 76$. QRYr3A.1 was identified in common wheat cultivar Saar and linked with markers Xbarc310 and Xstm844tcac (Lillemo et al. 2008). Based on the origin, effect, and linked markers, QYrzv. swust-3AS is unlikely the above previously reported QTL.

QYrsv.swust-4AL from Svevo was flanked by IWB11158 and IWB36731 on chromosome 4AL with a genetic distance of 1.19 cM. It explained 9.7 to $14.0 \%$ of the phenotypic variation in one environment in Israel and three environments in China in the BIP analysis. QYrsv.swust $4 A L$ was mapped in the durum genome region between $695,644,536$ and $696,576,349$ bp of chromosome 4A, corresponding to the $701,410,982$ - to $702,039,421$-bp region of the CS 4AL. Thus far, two formally named stripe rust genes, $\operatorname{Yr} 51$ and Yr60, conferring ASR and APR, respectively, have been reported on 4AL (Herrera-Foessel et al. 2015; Randhawa et al. 2014). According to the origin, resistance type, or linked markers, QYrsv.swust-4AL is different from either $\operatorname{Yr} 51$ or $\operatorname{Yr60}$. In addition, 13 other QTL for stripe rust resistance have also been mapped to chromosome 4AL (Supplementary Table S3). Based on the flanking markers of the four QTL, QYrid.ui-4A, QYr.orr-4AL, QYrns.orz-4AL, and QYren.orz$4 A L$ are located in the chromosomal bin 4AL4-0.80-1.00, which is the same region as $\operatorname{Yr} 51$ (Chen et al. 2012; Vazquez et al. 2012, 2015). According to the resistance source of each QTL, their effect, and linked markers, QYrsv.swust-4AL is probably different from these QTL. Further studies are needed to resolve the exact locations and the relationships of these QTL and QYrsv.swust-4AL.

Two QTL were identified on the long arm of chromosome 5A. QYrsv.swust-5AL.1 was mapped between markers IWA5118 and IWB60872 on the long arm of chromosome 5A in the 475,491, 560- to 483,079,171-bp region of the durum genome, corresponding to the region from $512,234,850$ to $519,885,280 \mathrm{bp}$ of the CS genome 5AL chromosome. QYrsv.swust-5AL. 2 was located between markers IWB71794 and IWB71147 on the long arm of chromosome 5A and was mapped to the $629,684,115$ - to $630,156,725$-bp region of the durum genome, corresponding to the $671,163,753$ - to $672,408,011-b p$ region of the CS genome 5AL chromosome. Thus far, more than 13 genes and QTL have been reported on chromosome 5AL, including Yr34 and Yr48 (Supplementary Table S3). Yr34 confers ASR (Bariana et al. 2006), whereas $Y r 48$ confers APR (Lowe et al. 2011). Based on the flanking markers, $Y r 48$ can be assigned to the CS deletion bin 5AL23-0.87-1.00, corresponding to the region between $698,638,215$ and 705,446,229 bp. According to the pedigree, resistance types and level, or linkage markers, QYrsv.swust5AL.1 and QYrsv.swust-5AL.2 appear to be different from both Yr34 and $\operatorname{Yr} 48$ and are also unlikely to be the same as any of the previously reported QTL.

Based on the results of BIP analysis, all nine QTL explained more than $6 \%$ of the phenotypic variation, except for QYrsv.swust-3AS, which explained only $4.64 \%$ PVE. In comparison, the results from the MET method showed a lower PVE value than the BIP method for all nine QTL. The MET method has the advantage of using the data from all environments and, thus, its additive LOD (LOD_A) score indicates the stability of the individual QTL. The LOD scores from the MET analysis were higher than those from the BIP analysis; therefore, the significance thresholds are higher ( $\mathrm{Li}$ et al. 2015). However, PVE estimates from the MET analysis are usually lower than those from the BIP analysis. The QTL identified by the BIP analysis scanning each environment separately could not account for the 11 environments observed in the present study. The MET analysis pointed to the phenotypic variance explained by individual QTL in additional environments that were not detected by BIP. The QTL identified in additional environments were due to the high power of the MET analysis. The discovery of 13 marker pairs that show digenic epistasis QTL (LOD > 20) in the present study may provide a more clear picture and explain why Svevo is highly resistant to stripe rust, while none of the RILs in the mapping population 
had the same resistance level. The complexity of the genetics underlying the Svevo resistance to stripe rust may complicate the transfer of the resistance to other cultivars. However, the problem could be solved, at least partially, by genomic selection.

\section{Literature Cited}

Avni, R., Nave, M., Barad, O., Baruch, K., Twardziok, S. O., Gundlach, H., Hale, I., Mascher, M., Spannagl, M., Wiebe, K., and Jordan, K. W. 2017. Wild emmer genome architecture and diversity elucidate wheat evolution and domestication. Science 357:93-97.

Avni, R., Nave, M., Eilam, T., Sela, H., Alekperov, C., Peleg, Z., Dvorak, J., Korol, A., and Distelfeld, A. 2014. Ultra-dense genetic map of durum wheat $\times$ wild emmer wheat developed using the $90 \mathrm{~K}$ iSelect SNP genotyping assay. Mol. Breed. 34:1549-1562.

Bansal, U. K., Kazi, A. G., Singh, B., Hare, R. A., and Basiana, H. S. 2014. Mapping of durable stripe rust resistance in a durum wheat cultivar Wollaroi. Mol. Breed. 33:51-59.

Bariana, H. S., Parry, N., Barclay, I. R., Loughman, R., McLean, R. J., Shankar, M., Wilson, R. E., Willey, N. J., and Francki, M. 2006. Identification and characterization of stripe rust resistance gene $\mathrm{Yr} 34$ in common wheat. Theor. Appl. Genet. 112:1143-1148.

Cao, X., Zhou, J., Gong, X., Zhao, G., Jia, J., and Qi, X. 2012. Identification and validation of a major quantitative trait locus for slow-rusting resistance to stripe rust in wheat. J. Integr. Plant Biol. 54:330-344.

Chen, J., Chu, C., Souza, E. J., Guttieri, M. J., Chen, X., Xu, S., Hole, D., and Zemetra, R. 2012. Genome-wide identification of QTL conferring hightemperature adult-plant (HTAP) resistance to stripe rust (Puccinia striiformis f. sp. tritici) in wheat. Mol. Breed. 29:791-800.

Chen, X. M. 2005. Epidemiology and control of stripe rust (Puccinia striiformis $\mathrm{f}$. sp. tritici) on wheat. Can. J. Plant Pathol. 27:314-337.

Chen, X. M. 2020. Pathogens which threaten food security: Puccinia striiformis, the wheat stripe rust pathogen. Food Secur. 12:239-251

Chen, X. M., Coram, T., Huang, X. L., Wang, M. N., and Dolezal, A. 2013. Understanding molecular mechanisms of durable and non-durable resistance to stripe rust in wheat using a transcriptomics approach. Curr. Genomics 14: $111-126$.

Cheng, J., Yan, J., Sela, H., Manisterski, J., Lewinsohn, D., Nevo, E., and Fahima, T. 2010. Pathogen race determines the type of resistance response in the stripe rust-Triticum dicoccoides pathosystem. Physiol. Plant. 139:269-279.

Cobo, N., Pflüger, L., Chen, X. M., and Dubcovsky, J. 2018. Mapping QTL for resistance to new virulent races of wheat stripe rust from two Argentinean wheat cultivars. Crop Sci. 58:2470-2483.

Cobo, N., Wanjugi, H., Lagudah, E., and Dubcovsky, J. 2019. A high-resolution map of wheat $Q Y r . u c w-1 B L$, an adult plant stripe rust resistance locus in the same chromosomal region as $\operatorname{Yr29}$. Plant Genome 12:180055.

Helguera, M., Khan, I. A., Kolmer, J., Lijavetzky, D., Zhong-qi, L., and Dubcovsky, J. 2003. PCR assays for the Lr37-Yr17-Sr38 cluster of rust resistance genes and their use to develop isogenic hard red spring wheat lines. Crop Sci. 43:1839-1847.

Herrera-Foessel, S. A., Singh, R. P., Huerta-Espino, J., Salazar, V. C., and Lagudah, E. S. 2011. First report of slow rusting gene Lr46 in durum wheat. Page 191 in: Proc. Borlaug Global Rust Initiative, St. Paul, MN, U.S.A.

Herrera-Foessel, S. A., Singh, R. P., Lan, C. X., Huerta-Espino, J., Calvo-Salazar, V., Bansal, U. K., Bariana, H. S., and Lagudah, E. S. 2015. Yr60, a gene conferring moderate resistance to stripe rust in wheat. Plant Dis. 99:508-511.

Hou, L. Y., Jia, J. Q., Zhang, X. J., Li, X., Yang, Z. J., Ma, J., Guo, H. J., Zhan, H. X., Qiao, L. Y., and Chang, Z. J. 2016. Molecular mapping of the stripe rust resistance gene $\operatorname{Yr} 69$ on wheat chromosome 2AS. Plant Dis. 100:1717-1724.

Kolmer, J. A. 2015. A QTL on chromosome 5BL in wheat enhances leaf rust resistance of Lr46. Mol. Breed. 35:74-81.

Lan, C., Li, Z., Herrera-Foessel, S. A., Huerta-Espino, J., Basnet, B. R., Dreisigacker, S., Ren, Y., Lagudah, E., and Singh, R. P. 2019. Identification and mapping of two adult plant leaf rust resistance genes in durum wheat. Mol. Breed. 39:118.

Lan, C., Zhang, Y., Herrera-Foessel, S. A., Basnet, B. R., Huerta-Espino, J., Lagudah, E. S., and Singh, R. P. 2015. Identification and characterization of pleiotropic and co-located resistance loci to leaf rust and stripe rust in bread wheat cultivar Sujata. Theor. Appl. Genet. 128:549-561.

Li, H. Y., Bariana, H., Singh, D., Zhang, L. Q., Dillon, S., Whan, A., Bansal, U., and Ayliffe, M. 2020. A durum wheat adult plant stripe rust resistance QTL and its relationship with the bread wheat $\operatorname{Yr} 80$ locus. Theor. Appl. Genet. 133: 3049-3066.

Li, J., Dundas, I., Dong, C., Li, G., Trethowan, R., Yang, Z., Hoxha, S., and Zhang, P. 2020. Identification and characterization of a new stripe rust resistance gene Yr83 on rye chromosome 6R in wheat. Theor. Appl. Genet. 133:1095-1107.

Li, S., Wang, J., and Zhang, L. 2015. Inclusive composite interval mapping of QTL by environment interactions in biparental populations. PLoS One 10:e0132414.

Lillemo, M., Asalf, B., Singh, R. P., Huerta-Espino, J., Chen, X. M., He, Z. H., and Bjørnstad, $\AA$. 2008. The adult plant rust resistance loci $L r 34 / Y r 18$ and $L r 46 /$ Yr29 are important determinants of partial resistance to powdery mildew in bread wheat line Saar. Theor. Appl. Genet. 116:1155-1166.
Lin, X., N'Diaye, A., Walkowiak, S., Nilsen, K. T., Cory, A. T., Haile, J., Kutcher, H. R., Ammar, K., Loladze, A., Huerta-Espino, J., Clarke, J. M., Ruan, Y. F., Knox, R., Fobert, P., Sharpe, A. G., and Pozniak, C. J. 2018. Genetic analysis of resistance to stripe rust in durum wheat (Triticum turgidum L. var. durum). PLoS One 13:e0203283.

Line, R. F., and Qayoum, A. 1992. Virulence, aggressiveness, evolution and distribution of races of Puccinia striiformis (the cause of stripe rust of wheat) in North America, 1968-1987. U.S. Dep. Agric. Tech. Bull. 1788.

Lowe, I., Jankuloski, L., Chao, S., Chen, X., See, D., and Dubcovsky, J. 2011 Mapping and validation of QTL which confer partial resistance to broadly virulent post-2000 North American races of stripe rust in hexaploid wheat. Theor. Appl. Genet. 123:143-157.

Ma, D. F., Fang, Z. W., Lin, J. L., Chao, K. X., Jing, J. X., Li, Q., and Wang, B. T. 2016. Molecular mapping of stripe rust resistance gene $\mathrm{YrHu}$ derived from Psathyrostachys huashanica. Mol. Breed. 36:64.

Maccaferri, M., Harris, N. S., Twardziok, S. O., Pasam, P. K., Gundlach, H., Spannagl, M., Ormanbekova, D., Lux, T., Prade, V. M., Milner, S. G., Himmelbach, A., Mascher, M., Bagnaresi, P., Faccioli, P., Cozzi, P., Lauria, M., Lazzari, B., Stella, A., Manconi, A., Gnocchi, M., Moscatelli, M., Avni, R., Deek, J., Biyiklioglu, S., Frascaroli, E., Corneti, S., Salvi, S., Sonnante, G., Desiderio, F., Marè, C., Crosatti, C., Mica, E., Özkan, H., Kilian, B., Vita P. D., Marone, D., Joukhadar, R., Mazzucotelli, E., Nigro, D., Gadaleta, A., Chao, S., Faris, J. D., Melo, A. T. O., Pumphrey, M., Pecchioni, N., Milanesi, L., Wiebe, K., Ens, J., MacLachlan, R. P., Clarke, J. M., Sharpe, A. G., Koh, C. S., Liang, K. Y. H., Taylor, G. J., Knox, R., Budak, H., Mastrangelo, A. M. Xu, S. S., Stein, N., Hale, I., Distelfeld, A., Hayden, M. J., Tuberosa, R., Walkowiak, S., Mayer, K. F. X., Ceriotti, A., Pozniak, C. J., and Cattivelli, L. 2019. Durum wheat genome highlights past domestication signatures and future improvement targets. Nat. Genet. 51:885-895.

Maccaferri, M., Ricci, A., Salvi, S., Milner, S. G., Noli, E., Martelli, P. L., Casadio, R., Akhunov, E., Scalabrin, S., Vendramin, V., Ammar, K., Blanco, A., Desiderio, F., Distelfeld, A., Dubcovsky, J., Fahima, T., Faris, J., Korol, A., Massi, A., Mastrangelo, A. M., Morgante, M., Pozniak, C., N’ Diaye, A., Xu, S., and Tuberosa, R. 2015a. A high-density, SNP based consensus map of tetraploid wheat as a bridge to integrate durum and bread wheat genomics and breeding. Plant Biotechnol. J. 13:648-663.

Maccaferri, M., Zhang, J., Bulli, P., Abate, Z., Chao, S., Cantu, D., Bossolini, E., Chen, X., Pumphrey, M., and Dubcovsky, J. 2015b. A genome-wide association study of resistance to stripe rust (Puccinia striiformis f. sp. tritici) in a worldwide collection of hexaploid spring wheat (Triticum aestivum L.). G3. Gene Genet. Genomics 5:449-465.

McIntosh, R. A., Dubcovsky, J., Rogers, W. J., Morris, C. F., Appels, R., and Xia, X. C. 2017. Catalogue of gene symbols for wheat, supplement. https:// shigen.nig.ac.jp/wheat/komugi/genes/symbolClassList.jsp

McIntosh, R. A., Yamazaki, Y., Dubcovsky, J., Rogers, J., Morris, C., Appels, R., and Xia, X. C. 2013. Catalogue of gene symbols for wheat. http:// www.shigen.nig.ac.jp/wheat/komugi/genes/download.jsp

Meng, L., Li, H. H., Zhang, L. Y., and Wang, J. K. 2015. QTL IciMapping: Integrated software for genetic linkage map construction and quantitative trait locus mapping in biparental populations. Crop J. 3:269-283.

Pakeerathan, K., Bariana, H., Qureshi, N., Wong, D., Hayden, M., and Bansal, U. 2019. Identification of a new source of stripe rust resistance $\operatorname{Yr} 82$ in wheat. Theor. Appl. Genet. 132:3169-3176.

Ponce-Molina, L. J., Huerta-Espino, J., Singh, R. P., Basnet, B. R., Lagudah, E., Aguilar-Rincón, V. H., Alvarado, G., Lobato-Ortiz, R., Garcia-Zavala, J., and Lan, C. X. 2018. Characterization of adult plant resistance to leaf rust and stripe rust in Indian wheat cultivar New Pusa 876. Crop Sci. 58:630-638.

Randhawa, M., Bansal, U., Valárik, M., Klocová, B., Doležel, J., and Bariana, H. 2014. Molecular mapping of stripe rust resistance gene $\mathrm{Yr} 51$ in chromosome 4AL of wheat. Theor. Appl. Genet. 127:317-324

Singh, A., Pandey, M. P., Singh, A. K., Knox, R. E., Ammar, K., Clarke, J. M., Clarke, F. R., Singh, R. P., Pozniak, C. J., DePauw, R. M., McCallum, B. D. Cuthbert, R. D., Randhawa, H. S., and Fetch, T. G. 2013. Identification and mapping of leaf, stem and stripe rust resistance quantitative trait loci and their interactions in durum wheat. Mol. Breed. 31:405-418.

The International Wheat Genome Sequencing Consortium (IWGSC), Appels, R., Eversole, K., Stein, N., et al. 2018. Shifting the limits in wheat research and breeding using a fully annotated reference genome. Science 361:eaar7191.

Vazquez, M. D., Peterson, C. J., Riera-Lizarazu, O., Chen, X., Heesacker, A., and Mundt, C. 2012. Genetic analysis of adult plant, quantitative resistance to stripe rust in wheat cultivar 'Stephens' in multi-environment trials. Theor. Appl. Genet. 124:1-11.

Vazquez, M. D., Zemetra, T., Peterson, C. J., Chen, X. M., Heesacker, A., and Mundt, C. C. 2015. Multi-location wheat stripe rust QTL analysis: Genetic background and epistatic interactions. Theor. Appl. Genet. 128:1307-1318.

Wang, J. K. 2009. Inclusive composite interval mapping of quantitative trait genes Acta Phytopathol. Sin. 35:239-245.

Wang, S., Wong, D., Forrest, K., Allen, A., Chao, S., Huang, B. E., Maccaferri, M., Salvi, S., Milner, S. G., Cattivelli, L., Mastrangelo, A. M., Whan, A., Stephen, S., Barker, G., Wieseke, R., Plieske, J., International Wheat Genome Sequencing Consortium, et al. 2014. Characterization of polyploid wheat genomic diversity using a high-density 90,000 single nucleotide polymorphism array. Plant Biotechnol. J. 12:787-796. 
William, M., Singh, R. P., Huerta-Espino, J., Islas, S. O., and Hoisington, D. 2003. Molecular marker mapping of leaf rust resistance gene $\operatorname{Lr} 46$ and its association with stripe rust resistance gene $\mathrm{Yr} 29$ in wheat. Phytopathology 93:153-159.

Wu, J. H., Wang, Q. L., Chen, X. M., Wang, M. J., Mu, J. M., Lv, X. N., Huang, L. L., Han, D. J., and Kang, Z. S. 2016. Stripe rust resistance in wheat breeding lines developed for central Shaanxi, an overwintering region for Puccinia striiformis f. sp. tritici in China. Can. J. Plant Pathol. 38:317-324.

Xiang, C., Feng, J. Y., Wang, M. N., Chen, X. M., See, D. R., Wan, A. M., and Wang, T. 2016. Molecular mapping of stripe rust resistance gene $\mathrm{Yr} 76$ in winter club wheat cultivar Tyee. Phytopathology 106:1186-1193.

Xu, L. S., Wang, M. N., Cheng, P., Kang, Z. S., Hulbert, S. H., and Chen, X. M. 2013. Molecular mapping of Yr53, a new gene for stripe rust resistance in durum wheat accession PI 480148 and its transfer to common wheat. Theor. Appl. Genet. 126:523-533.
Yang, M. Y., Li, G. R., Wan, H. S., Li, L. P., Li, J., Yang, W. Y., Pu, Z. J., Yang, Z. J., and Yang, E. N. 2019. Identification of QTLs for stripe rust resistance in a recombinant inbred line population. Int. J. Mol. Sci. 20:3410.

Zadoks, J. C., Chang, T. T., and Konzak, C. F. 1974. A decimal code for the growth stages of cereals. Weed Res. 14:415-421.

Zhou, X. L., Han, D. J., Chen, X. M., Hu, J. M., Xue, W. B., Zeng, Q. D. Wang, Q. L., Huang, L. L., and Kang, Z. S. 2015a. QTL mapping of adult-plant resistance to stripe rust in wheat line P9897. Euphytica 205 243-253.

Zhou, X. L., Hu, T., Li, X., Yu, M., Li, Y. Y., Yang, S. Z., Huang, K. B., Han, D. J., and Kang, Z. S. 2019. Genome-wide mapping of adult plant stripe rust resistance in wheat cultivar Toni. Theor. Appl. Genet. 132:1693-1704

Zhou, X. L., Zhan, G. M., Huang, L. L., Han, D. J., and Kang, Z. S. 2015b. Evaluation of resistance to stripe rust in eighty abroad spring wheat germplasms. Sci. Agric. Sin. 8:1518-1526. 